\title{
A Qualitative Analysis of Adult Children's Advice for Parents Coming Out to Their Children
}

\author{
Diana Breshears \\ University of Pretoria; \\ Carien Lubbe-De Beer \\ University of Pretoria
}

\begin{abstract}
Biographical Information for Authors: Diana Breshears received her $\mathrm{PhD}$ in Communication Studies from the University of Nebraska, Lincoln, specializing in Interpersonal and Family Communication. She is currently a postdoctoral fellow in Educational Psychology at the University of Pretoria. Her professional interests include the communicative creation and maintenance of identity among individuals with non-traditional, stigmatized familial identities.
\end{abstract}

Carien Lubbe-De Beer, $\mathrm{PhD}$, is an associate professor in Educational Psychology at the University of Pretoria. Her research interests include same-gendered (lesbian/gay) families. Other research areas include the exploration of asset-based and positive psychological approaches in Educational Psychology. Carien is currently involved in the training of psychological counselors (Honors program), as well as the supervision of the career psychology component in a Master's program.

Acknowledgement: Theauthorswouldliketothank Professor Dawn O. Brathwaite for her guidance and input throughout this research project.

Picture a man approaching his therapist for advice on coming out to his son. "My 6 year old asked his mother, my ex-wife, 'Mom, is dad gay?'. He's coming to visit this weekend, what do I tell him?" Research has shown that parents have many concerns when making this decision, such as how their children will react, what effect their sexual orientation may have on the children, what the children should share with their friends or at school, and so forth (Lynch \& Murray, 2000). Although many parents are faced with the situation of disclosing their sexual orientation to their children, generally there is little professional information to which parents can turn when trying to decide if, when, and how to come out. Similarly, practitioners currently have few professional resources guiding them through the complexities of lesbian and gay parenting. Though the American Psychological Association (2012) offers guidelines to aid practitioners in their work with LGB clients, the guidelines do not specifically address parents' sexual orientation disclosures to their children. The purpose of the current exploratory study was to begin to understand the experiences of children who had been conceived and raised in a heterosexual relationship, and whose parents only disclosed a lesbian or gay sexual orientation at a later stage in their lives. Through the eyes of these children invaluable recommendations for parents and practitioners could be formulated.

\section{Parental Disclosures of Sexual Orientation}

Sexual orientation disclosure (coming out) is often conceptualized as something that happens before people marry and have children. Therefore, only a handful of studies - many, decades old-have explored parents coming out to their children (e.g., Bozett, 1980; Clay, 1990; Lynch \& Murray, 2000; Turner, Scadden, \& Harris, 1990). From international literature, we know much about the context in which parental disclosures take place, but few studies have 
explored the content of the disclosures, and no studies have explored children's reflections/critique of the actual coming-out conversation.

From the few existing studies, we have some information about the motivation and timing that drive parents' decisions to come out or hide their sexual orientation from their children. Their motivations include ideas about the "right" age for children to learn about the parents" sexual orientation, parents' desire for children to understand their personal and social worlds, the level of difficulty in keeping the sexual orientation a secret, and parents' fear of losing custody of the children to their ex-spouses (Bozett, 1980; Lynch \& Murray, 2000; Weston, 1991). Parents also find it important to consider their children's reactions to the disclosures, and to control from whom the information comes (Goldberg, 2007; Lynch \& Murray, 2000; Patterson, 1995).

Parents receive a wide range of reactions from their children when disclosing their homosexuality, including anger, joking, thanking them for being honest, and refusing to talk about it (Turner, Scadden, \& Harris, 1990; Weston, 1991). Barrett and Tasker (2001) reported that daughters responded more sympathetically to their parents' disclosures than did their sons. Furthermore, researchers have found that younger children have the least difficulty accepting their parents' sexual orientation, while adolescents have the most difficulty (Lynch \& Murray, 2000; Patterson, 1992). It is interesting that parents in Turner, Scadden, and Harris's (1990) study noted that overall, their children were largely indifferent toward their sexual orientations, and the disclosure was less problematic than anticipated.

Although the existing literature provides important insights into the motivations and contexts of parents' coming out to their children, very little is known about the content of the comingout conversation. Further, no study has been designed with the practical aim of providing advice for parents who are planning to come out to their children. Here, we extend this line of research by beginning to explore the experiences of adults who have had a parent come out to them, and presenting the advice they have for parents based on these experiences.

\section{The Study}

The current study was approached using a phenomenological framework in which we sought to understand the essence of participants' experiences of having a parent come out to them, as well as their interpretations and meanings they place on these experiences (Creswell, 2007). Specifically, we were interested in participants' reflections of the coming-out conversations and the advice they have, based on these reflections, for parents who are preparing to come out to their own children. Participants in our study were 20 adult children who have had a parent come out to them. At the time of the interviews, participants' ages ranged from 22-40, with a mean age of 29 (see Table 1). During semistructured interviews, lasting 40-80 minutes, participants were asked to reflect on their experiences and answer the following questions:

Tell me the story of finding out that your parent is lesbian or gay. What would have been the ideal way to find out that your parent is lesbian or gay? What advice do you have for parents preparing to come out to their children?

Participants were recruited through network and snowball sampling based on two criteria. First, participants must have been legal adults at the time of the interview (defined as 19 
Table 1

Participant Demographics

\begin{tabular}{|c|c|c|c|c|c|c|}
\hline Participant* & Sex & Current age & Ethnicity & $\begin{array}{c}\text { Sexual } \\
\text { orientation }\end{array}$ & $\begin{array}{l}\text { Gay/lesbian } \\
\text { parent }\end{array}$ & Age at discovery \\
\hline Alexander & M & 23 & Caucasian & Queer & Mother & 19 \\
\hline Angela & $\mathrm{F}$ & 33 & Caucasian & Straight & Father & 16 \\
\hline Bethany & $\mathrm{F}$ & 26 & Caucasian & Straight & Mother & 16 \\
\hline Bette & $\mathrm{F}$ & 22 & Black/Panamanian & Straight & Mother & 8 \\
\hline Darlene & $\mathrm{F}$ & 23 & Caucasian & Straight & Father & 13 \\
\hline Derek & M & 24 & Caucasian & Straight & Father & 16 \\
\hline Devon & M & 29 & Caucasian & Straight & Father & 7 \\
\hline Gabrielle & $\mathrm{F}$ & 40 & Caucasian & Bisexual & Mother & 25 \\
\hline Gilbert & M & 34 & Caucasian & Gay & Mother & 15 \\
\hline Gloria & $\mathrm{F}$ & 27 & Caucasian & Straight & Father & 22 \\
\hline James & M & 30 & Caucasian & Straight & Father & 24 \\
\hline Julia & $\mathrm{F}$ & 39 & Caucasian & Straight & Mother & 32 \\
\hline Louise & $\mathrm{F}$ & 29 & Caucasian & Bisexual & Mother & 13 \\
\hline Lydia & $\mathrm{F}$ & 22 & Caucasian & Straight & Mother & 8 \\
\hline Megan & $\mathrm{F}$ & 30 & Caucasian & Straight & Mother & 22 \\
\hline Molly & $\mathrm{F}$ & 34 & Caucasian & Bisexual & Mother & 29 \\
\hline Rosa & F & 32 & Caucasian & Gay & Father & 18 \\
\hline Shelby & $\mathrm{F}$ & 30 & Caucasian & Straight & Mother & 5 \\
\hline Thomas & M & 29 & Caucasian & Straight & Father & 19 \\
\hline Tina & $\mathrm{F}$ & 24 & Caucasian & Straight & Mother & 19 \\
\hline
\end{tabular}

* Participant names have been changed to ensure confidentiality. 


\section{Table 2}

\section{Advice for Parents Coming Out to Their Children}

Before coming out

1. Consider the child's perspective/maturity

2. Give the child credit

3. Be comfortable with his/her own sexual orientation

4. Teach the child to accept differences

5. Tell the child early

6. Don't wait for the child to ask

During the coming-out conversation

1. Be open/honest

2. Expect/accept any reaction

3. Reassure the child

4. Tell the child what comes next

5. Expect questions

6. Only share what you are comfortable sharing

After coming out

1. Give the child time

2. Be gradual in the disclosure

3. Find community for the child and the parent

4. Provide the child with stability 
years old by the overseeing internal review board). Second, participants must have recalled and been able to discuss the time when they perceived their parents to be heterosexual, and remembered having a conversation with their lesbian/gay parents about the parents' sexual orientation. The call for participants was sent to people in our network that had access to lesbian and gay families, asking them to forward the recruitment script to potential participants. Additionally, the call was distributed using LGBT listserves on a large Midwestern university campus and online groups dedicated to LGBT families. When contact was made with participants, they were asked to forward the call to other potential participants they knew, such as siblings or friends. To protect the confidentiality of these individuals, participants were not asked to provide the names of potential participants, but rather to provide them with the researchers' contact information so that they may make contact if interested in taking part in the study.

The analytic induction method was used to analyze the data once they were transcribed, allowing for the emergence of themes and categories by comparing and contrasting the data during examination (Baxter \& Babbie, 2004). Specifically, Smith's (1995) 5-step guideline for thematic analysis was used to identify emergent themes. In the first step of this guideline, transcripts are read completely to familiarize the researcher with the data. Second, the researcher rereads each transcript, noting in one margin anything that "strikes [her] as interesting or significant about what the respondent is saying" (Smith, 1995, p. 19). In the other margin, the researcher documents emerging themes that speak to the research questions. In the third step, the researcher lists all of the emerging themes and looks for connections among them. As clusters of themes emerge, the researcher continually checks back with the transcripts to ensure that the connections also work with the source. Fourth, the researcher produces a master list of themes for each research question. Finally, the researcher adds an "identifier of instances" to the master list, indicating where in the transcripts the instances can be found (Smith, 1995, p. 20). Themes in this study were the various suggestions and advice participants had for parents during the process of coming out to their children.

To add to the validity of our findings, we held a collaborative data conference with four researchers trained in interpretive methodology and RDT. In the data conference (similar to Miles and Huberman's [1994] "audit") scholars worked together to check and refine the findings. Following the data conference, we engaged in member checking, during which all participants were provided with the findings and given the opportunity to correct misunderstandings or errors in researchers' conclusions (Creswell, 2007). Six of the 20 participants responded with their approval or requests for changes. All requests were incorporated into the final themes.

\section{Advice for Parents}

After participants shared their stories and reflected on having a parent come out to them, they were asked to bear these experiences in mind as they offered suggestions to parents who are considering coming out to their children. This question allowed the participants to build on their experiences and apply their personal insights in the form of suggestions. The suggestions offered by the participants naturally fit into three categories: what the parents can do/consider (a) prior to coming out, (b) during the coming-out conversation, and (c) after coming out (See Table 2 for a summary of participants' advice). 


\section{Before Coming Out}

Among the suggestions on considerations prior to coming out, there emerged a trend that the parent has to first give thought to the possible ramifications of coming out before having the conversation.

\section{Consider the child's perspective/maturity}

The most common suggestion offered by the participants for parents prior to the coming-out disclosure is to take the child's perspective and/or maturity into consideration as they decide when/what they should disclose. Some participants offering this suggestion believe that parents, especially those with young children, should be sure that the children are emotionally ready for the information. Tina, a 24-year-old woman whose mother came out to her 5 years ago, shared:

[Be sure] it's news that they think that the child is emotionally ready for, because it is a paradigm shift. ... There's plenty of chances in the news, or dinner table conversation to see what your kids think about ... homosexuality and to kind of gauge where they're at and just make sure that they're emotionally ready to have that talk.

Tina suggested that parents probe their children for their current views and understandings of homosexuality to know whether or not they are ready for that conversation. Bette, a 22 -yearold woman whose mother came out to her when she was eight years old, similarly explained:

Participant: Be considerate of your child's feelings.Interviewer: In what sense?Participant: As parents, you know what they've been preexposed to. You know what they haven't been exposed to ... You need to be considerate, because depending on the age of the child, they may be fragile to that situation. You need to know what you need to do and how you need to say it, and what's the best way you need to say it.

Bette and others believe that parents know their children well enough to predict possible reactions they may have to the coming out. They advise parents to think about the effects the disclosures may have on the children so they best know how to approach the topic and, in some cases, console their children after the disclosure.

\section{Give the child credit}

Participants further advised parents to have confidence in the children's character and in their resilience. In a sense, these participants claim that parents should not worry about their children's reactions. Alexander, a 23-year-old man whose mother came out to him 4 years ago, expressed that parents specifically should have confidence in their children as caring individuals. He shared:

I think the most important piece of advice is . . you have to put faith in the fact that you raised your children to be caring individuals. I mean, that's the only reason that I think I'm so comfortable with it. . . . My mom said, "I tried my best to raise you so that you wouldn't hate me when I was older." And I think that's important. You just kind of have to have faith in the people that you've raised. ... Your kids will love you, hopefully. 
In Alexander's experience, the fact that his mother raised him to be a caring, loving individual ultimately helped him accept her sexual orientation. Darlene, a 23-year-old woman who discovered that her father is gay when she was 13 years old, explained that children are able to adapt to many situations, even if they are difficult. She shared:

You know, the coming-out processes are going to happen for families in very different ways; they're going to look different ways, they're going to react in different ways, but I think that parents don't give their children enough credit for their resiliency and their ability to understand and adapt and create relationships that look different, but are still just as wonderful.

Though participants are aware that children will react in different ways to having a parent come out, in the end, they believe children will be able to adjust and continue to have positive relationships with their parents.

\section{Be comfortable with his or her own sexual orientation}

Participants also encouraged parents to have confidence in, and be comfortable with, their sexual orientation. The participants with this suggestion explained that the parents' lack of confidence would directly influence the reactions of their children. Shelby, a 30-year-old woman whose mother came out to her when she was 5 years old, explained:

My piece of advice for any parent coming out would be for them to be comfortable with themselves. Because I think if they're not comfortable being who they are yet, then it's really going to do a disservice to their children. If my mom would have acted like she was ashamed, or guilty, or something like that, I would perceive it that way as well.

Shelby claims that children will have a difficult time accepting their parents' sexual orientation if the parents cannot accept it for themselves. Angela, a 33-year-old woman whose father came out to her when she was 16 years old, had come to a similar conclusion. She explained, "Don't show that you're ashamed 'cause if you show that you're ashamed, your children might get that vibe too. Be proud of who you are." Participants claimed that children will reflect any discomfort or shame they see in their parents, and therefore, parents should be confident in their identities prior to coming out to the children so the children can also be comfortable and confident.

\section{Teach the child to accept differences}

Some participants argued that the best thing parents can do is to teach their children to accept differences in people. According to these participants, if the children are taught from a young age to have an open mind toward differences, they will be more open and accepting of their parents when they come out. Thomas, a 29-year-old man whose father came out to him when he was 19 years old, was taught that homosexuality was acceptable from a young age. He credits those teachings to his acceptance of his father's sexual orientation. He explained:

Given the way that I was raised from an early age to have an accepting view of homosexuality, with me being accepting of our new family situation, was something that was sort of a natural. ... This is the advice that I would give to parents is to raise their kids with an accepting view of other people because all people are different and there are gay people 
and straight people and, you know, we shouldn't be antigay or discriminate against people. People are people.

Overall, participants urged parents with younger children to instill an acceptance of difference in their children. Eventually, parents will be able to appeal to these values when coming out.

\section{Tell the child early}

Another suggestion participants had for parents who are preparing to come out to their children was that parents come out to their children as early as possible. Rosa, a 32-year-old woman, shared this suggestion: "Do it as early as possible. You know, as soon as you realize or as soon as your children are old enough ... just to avoid that thing I was saying earlier about feeling lied to." After Rosa's father came out to her when she was 18 years old, she struggled with the feeling of her family life being a façade that was put on to convince the world that they were a "normal" family. Rosa believed that she was lied to because her father kept his sexual orientation hidden for so long, which motivated her to advise parents to come out to their children at the earliest appropriate time possible. Though it may be difficult to determine the earliest appropriate time, parents could use the child's maturity or readiness as a guide (see suggestion 1).

\section{Don't wait for the child to ask}

While sharing their stories, respondents were sometimes disappointed when their lesbian/gay parents were not the ones to initiate the coming-out conversation, but rather they had to approach their parents or they were told about their parents' sexual orientation by a third party. Derek, a 24-year-old man whose father came out to him when he was 16 years old shared,

I wish my dad would have been more upfront about it and came to me about it, instead of us having to say, "Are you gay?" . . I knew at that time if I were going to get an answer, I'd have to ask the question. That's what I would have liked to be different. You know, he had known his partner for 4 years at that point. I wish that it would have been easier to explain the situation to us rather than us having to ask questions about it.

Derek and others would have preferred their parents to take the initiative rather than waiting to be approached about their sexual orientation.

\section{During the Coming-Out Conversation}

Participants offered seven suggestions that parents can do and/or take into consideration during the conversations in which they come out to their children.

\section{Be open/honest}

The majority of the participants said that parents should be open and honest with their children during the coming-out conversation. Participants overwhelmingly believed that, despite the immediate discomfort it may cause, parents' honesty about their sexual orientation will be better for the entire family in the end. Thomas, a 29-year-old man whose father came out to him when he was 19 years old, only learned that his parents had been 
having issues in their marriage after his father came out. He explained that he wished they had been honest with him and shared, "I think that just openness and honesty are vital elements of the coming-out process despite how difficult it might be." Some participants mentioned that children often know that something out of the ordinary is happening within the family, even if they are not aware that it is caused by the sexual orientation of their parents. Therefore, they have come to the conclusion that parents should be open with their children about what that something is. Megan, a 30-year-old woman whose mother came out to her when she was 22 years old, expressed this view when she said, "You know, through my experience, the majority of kids who have had their parents come out to them, the kids already know what's going on. So, take a deep breath, be honest, and be straightforward about it." Overall, participants expressed a preference for parents to be honest with their children and to be open with them about what the parents are going through. By being open with their children, lesbian and gay parents can set a positive example for children to be honest and true to themselves, living a life of integrity.

\section{Expect/accept any reaction}

Many participants recommended that parents should expect and accept any reaction from their children. These participants believe it is important for parents to not only refrain from predicting how their children will react when they come out to them, but also to accept and validate any reaction that their children may have. Gilbert, a 34-year-old man who discovered that his mother is a lesbian when he was 15 years old, shared, "This is very important. Be prepared for any type of reaction whatsoever. Even your own kids might have their own prejudices that you don't know about. They have to be prepared for that." Megan echoed the claim that children react differently, and that the reactions may not be what the parents hope. She explained:

People are all going to react different. Hopefully they'll go through the five stages of acceptance and be able to maintain the relationship.... If you have to give people time and let them grow into acceptance, and if they don't, you have to be able to accept that.

Megan and others emphasized that complete acceptance of the parents' sexual orientation is a process that takes time. Overall, participants wanted to warn parents that their children may not react in the way that they hope, and that they need to be prepared for possible rejection, even if that rejection is temporary. Further, they stressed that children need to be free to have their genuine reactions and parents should allow them the space for that to happen. This nonjudgmental acceptance of the child's reaction is necessary to keep the relationship and conversation open after the coming-out event itself.

\section{Reassure the child}

Participants further urged parents to reassure their children of their love and of the stability of their future. When asked to provide advice for parents coming out to their children, Gilbert replied, "Tell your children that you love them always, and that 'my being gay or lesbian isn't going to change that ever." Shelby offered a similar suggestion, responding, "But the kid needs to know that they still love them, and it's okay regardless of how long it takes them to accept it." In addition to reassuring the children that they are loved, participants believed that parents should also reassure the children that they are not losing their families as a result of the parent coming out. Julia stressed that parents should assure their children that things will not completely fall apart as a result of the parent coming out. She extended this suggestion by 
encouraging parents to use traditions and routines to create a sense of continuity and normalcy for the children. She explained:

Don't change. You know, keep some normalcy. Children thrive on normalcy, and this is something that you always do. You know, if you have a family tradition, keep it, because that's going to give them a sense of security that even though my mom came out of the closet, she's still the same mom I've always known.

Overall, participants expressed that children need to know that, though there may be some changes within the family as a result of their parents coming out, their parents will always love them and be part of their lives. Participants believe that including these assurances in the coming-out conversation will help the children come to terms with their parents' sexual orientation and the changes that may come with them. They emphasized that explicit expressions of love and support could be vital during these conversations. Leaving these things unspoken may detract from the children's peace of mind, especially in the light of uncertainty they may experience.

\section{Tell the child what comes next}

Several participants advised parents to tell their children what will happen as a result of the parents' coming out. Bette shared this suggestion when she explained, "Then you need to say how things are going to change. How will things change? . . That stuff is really important." She believes that, after a parent discloses her/his sexual orientation, children need to know what comes next. Rosa also advised parents to tell the children what will happen as a result of the coming out, and adds that parents should include the children in these decisions. She explained:

Yeah, I think discuss the next steps after you tell your child. What I mean is, don't just tell your child and then go off and do your own thing about how you tell everybody else. Once you tell your child, they then need to be part of the conversation about what happens next.

Participants represented in this category consider it imperative that parents reduce their children's uncertainty by telling them what will and will not change as a result of the parent coming out. Further, it would benefit children to be part of the conversation, with their voices and opinions being heard and considered.

\section{Expect questions}

Participants urged parents to expect questions from their children and predict what these questions may be. Gloria, a 27-year-old woman whose father came out to her when she was 22 years old, claimed that parents should anticipate these questions and attempt to understand what their children may be wondering as they come out. She explained:

I would say that parents need to be honest and to be ready to answer questions. And that your kids might not be comfortable asking the questions that they want to ask, but be prepared to answer them or to understand what they might be wondering. For example, "Have you felt this your whole life? Is this something you've always known? What were you thinking when you married my mom or my dad? What were you thinking?" Your kids are going to have questions. Just be ready to answer them. Even if you're not sure what the answers are, just say "I don't know what I was thinking" or something like that. 
In addition to expecting questions from their children, Gloria believes that parents should be willing to provide answers to these questions. Similarly, Derek claimed that parents should be willing to answer their children's questions as long as they are comfortable doing so. He shared, "I would also be sure to give the people a chance to learn more about it . . . to answer questions they feel comfortable answering." Participants believe that parents will be better prepared for their coming-out conversations if they expect questions from their children. Further, if parents consider possible questions their children may have, they can spend time thinking about their responses prior to the actual conversations with their children.

\section{Only share what you are comfortable sharing}

The final suggestion offered by participants for parents during the coming-out conversations with their children came from Derek and Julia. They claimed that parents do not have to share everything with their children and recommended that parents only share what they are comfortable sharing. Derek explained:

I would start off by saying that it's a choice that they had made that they can share with their family as much or as little as they want. It's still their choice whether or not they share it in the first place. I would want them to be comfortable explaining it, maybe practicing how they are going to explain it.

Derek acknowledged that, ultimately, parents have control over the information that is disclosed in the coming-out conversations, and they should not make the situation too uncomfortable for themselves. Julia also acknowledged that the parents have final say in what is disclosed to the children, and reminded parents that they do not have to disclose everything in that initial conversation. She shared, "You don't need to tell them everything. You know, let them ask questions. You don't have to divulge all the information. Let them know what they need to know and save the rest." Ultimately, these participants believe that parents need to have confidence in their coming-out conversations, and thus should only share what they are comfortable sharing. Parents need to be mentally prepared to try and control the amount of information that is initially disclosed, according to their own comfort levels. After the disclosure, children can ask for more information and parents can continue to use discretion in their decisions regarding what to share.

\section{After Coming Out}

In the interviews, participants offered four suggestions that parents can do and/or take into consideration after the initial coming-out conversation with their children.

\section{Give the child time}

The most common suggestion that participants had was for parents to give the children time to process the information. Participants acknowledged that having a parent tell you that she/he is lesbian/gay is a lot of information to process. Lydia, a 22-year-old woman whose mother came out to her when she was 8 years old, suggested that parents give their children time to process the information and changes within their families. She stated:

Another piece of advice would be to just give it time. I think it takes kids a lot of time to get used to new family situations. So to give it time and to be really stable and consistent while you're giving them time. 
Molly, a 34-year-old woman whose mother came out to her 5 years ago, also urged parents to give their children time to come to full acceptance of their parents' sexual orientation, relaying the suggestion she heard from a radio program. She shared:

Oh, one really good piece of advice that I've heard from [a radio station], don't expect the acceptance to come before the amount of time it took for you to find out that you were gay, or for you to learn it yourself. It could take family or friends that long to accept you.

Through the words of the radio program, Molly reminds parents that, much like it was a process for them to come to terms with their own sexual orientation, their children also have to go through a process of acceptance. Thinking about how long it took for them to accept their own identities can put their children's process of acceptance into perspective for the parents and encourage them to have patience as their children come to terms with their sexual orientation.

\section{Be gradual in the disclosure}

Some participants advised parents to be gradual in subsequent disclosures of information to their children. According to these participants, it is good for parents to tell the children that they are lesbian/gay, but the disclosure of additional information, such as relationships that the parents are in, may best be saved for a later time. Tina explained that, while she was glad that her mother came out to her, she was also glad that she was not overloaded with too much information to process during that conversation. She shared:

[Don't] go into a lot of detail about why. ... To me, it was kind of like I had to take the layers and, you know, as I got more comfortable about how that changed my identity, I was able to have those discussions. I kind of like the way my mom was short and simple with it. "Hey, I believe I'm gay" and I was able to process it and it wasn't overload.

Similar to Tina's suggestion, Bette also claimed that parents should be gradual in the information they share with their children. She explained, "I would tell them, take gradual steps. You can't just spill the whole pot of beans in one day. You know, you need to take steps. Make them understand how this came about, why it came about." As participants suggested in the previous section, many children need time to process their parents' sexual orientation. Participants claimed that giving children too much information to process could overwhelm the children, making the process more difficult.

\section{Find community for the parent and for the child}

The third suggestion for parents was to find community, or fellowship with people in similar situations, both for the children and for themselves. Participants explained that it benefits children to interact with others who have similar experiences. Devon, a 29 -year-old man who learned that his father was gay at the age of 8, explained that these groups not only benefit children by showing them the similarities of their experiences with others, but also help children learn how to handle any discrimination they may face as a result of having lesbian/gay parents. He shared:

Plug them in with groups like PFLAG [Parents, Families and Friends of Lesbians and Gays] or any other type of support group. It can help them kind of cope with the possibilities of stereotypes and some sort of discrimination, or just dealing with it in general. 
By involving children with groups through which they are exposed to other children of lesbian/gay parents, parents can provide their children with valuable resources and support as they navigate what it means to have lesbian/gay parents.

In addition to advising parents to involve their children in groups for LGBT families, participants suggested that parents find community for themselves. James, a 30-year-old man whose father came out to him 6 years ago, explained that parents who are coming out would benefit from receiving support from others. He shared:

I would say, find people that are going to be real friends. ... Find people who you can be honest with, who you can have relationships with, and that person can have relationships with your family, like a community thing. People get kind of crazy when they're isolated as families or as individuals.

James acknowledged the need lesbian and gay individuals have for community and support. Without it, he believes that people may go into isolation. As society often seems to provide negative feedback regarding homosexuality, community with others may change the perception that "all of society" is against homosexuality. Thus, for parents, it is important to find support and to incorporate that support into the family unit.

\section{Provide the child with stability}

The final piece of advice for parents was to keep some sense of stability within the family unit after the coming-out conversation. Thomas explained, "I think that finding ways to sort of keep the relationship among the family stable despite the upheaval that it might cause. I think that that's an absolute necessity." James also shared his wish that his dad would have remained close with the family after coming out. He explained:

In the long term, I wish he would have stayed more connected with us. He built a lot of, "I don't know what dad's doing. That's ok, that's who dad is." He's sort of alienated. . . So, I guess, if I could wave a magic wand over it, and adjust things from that day forward, I wish I would have had some more conversations with him. I really would have wished that he would have come out and remained in a more formal relationship with my mom for a time. . . I would have liked that a lot.

Respondents feel that too much change in their relationship with their parent and/or the family structure may make it difficult for children to adjust to their parents" "new" sexual orientation.

\section{Implications for Practitioners}

Practitioners, specifically psychologists, play an important role in facilitating discussions with clients about various issues, in order to help parents decide the route to take in the coming-out process. Psychology professionals have vast knowledge of human development, family dynamics, communication skills, minority issues, and cultural contexts to skillfully guide parents in finding their own solutions. It is important to note that the suggestions provided by the participants may not be applicable to all situations and different aspects of the situation should be taken into consideration, such as age and maturity of the children. Further, given the small sample size, these findings should not be taken as generalizable, nor 
prescriptive. Instead, these reflections could provide practitioners with a place to begin talking through important issues with their clients and offer parents a place to begin thinking about what may or may not benefit their children throughout the coming-out process. These suggestions are in line with previous research in which authors claimed that parents have to take into consideration different variables when deciding when and how to best come out to their children (Lynch \& Murray, 2000; Weston, 1991). It is also important to note that these suggestions are for parents who have made the decision to disclose their sexual orientation to their children. Coming out is not preferable for all people or in all situations, and practitioners should never pressure an individual to come out before she/he is ready to make that step.

- It is imperative that parents and practitioners view coming out as a process rather than a specific event. As such, continual guidance might be needed to guide the family through adapting to various changes. Key aspects can be discussed beforehand with a practitioner in order for the parent(s) to gain perspective and insight, such as events prior to and following a formal coming-out conversation. As suggested by the children, the parents need to be especially mindful of the child's needs throughout the entire disclosure process.

- Practitioners should prepare parents to console and provide empathetic support following disclosure, which implies that the parents themselves should be resourceful in terms of their own inner strength. Practitioners can therefore explore a parent's own level of comfort and self confidence in their own sexual orientation, in order to exude confidence in their children's ability to handle the disclosure. Furthermore, while the participants in the current study tell parents to reassure the child that their world will not fall apart as a result of the parent coming out, parents should be aware and prepared to console the child if difficult situations do arise as a result of the parent's disclosure (e.g., divorce, legal battles, etc.).

- Practitioners can reflect with parents on how aware and accepting of diversity the children are and work toward providing a positive sense of identity for the children. Practitioners can guide parents to engage with their children in conversations about various socially constructed categories such as gender, religion, race, and so forth, and the beliefs, myths, and stereotypes that are placed on these categories, to help put sexual orientation into perspective.

- Practitioners need to engage in self-reflexivity, acknowledging their own ignorance, possible stereotypes, and prejudices. As is the case with any client, respect and tolerance should be at the forefront of any discussion. If practitioners find themselves incapable of creating such an environment, the client should be referred to another practitioner.

- Practitioners guiding parents in an exploration of support structures for each individual in the family can enhance the family's resilience overall. Knowing, for example, a child's friends, the way the friends perceive diversity, and how they speak about LGBT individuals can provide the parent with insight as to how a child might be supported at school or when visiting friends. Awareness of empathetic teachers that might observe the child's resiliency, or other sources of support for a child might also help with her/his adaptation to the change in family structure. Further, practitioners and parents need to be prepared to offer support to the child in the case that she/he does experience discrimination for having a lesbian/gay parent.

- It is imperative that practitioners move beyond the notion that coming out is an individual activity, and focus on coming out as a familial process. Providing a protected space to explore disclosure not only for parents alone, but also for the whole family to reflect and share experiences, can be very healing. 
- Based on participants' emphasis on the need for parents to be open and honest, practitioners can reaffirm the notion of authentic and functioning relationships, which are based on honesty, openness, transparency, truthfulness, and acceptance of each family member's functioning at a given time.

\section{Limitations and Future Directions}

Though the current study serves as a starting point to provide a much-needed resource for practitioners regarding lesbians and gay men coming out to their children, it is not without its limitations. The first limitation of our study concerns the small sample size. Though it is not the goal of qualitative research to produce findings that are generalizable to the larger population (Cresswell, 2007), the study would have benefited from a larger number of participants. Future researchers and practitioners would benefit from gathering advice from larger samples of children with lesbian and gay parents, as well as utilizing a variety of assessment methods to provide more thorough resources for parents and practitioners. Second, though we were able to obtain gender and regional diversity within the United States, all but one participant in the study identified as White. Future research should seek a more representative sample of participants both within the larger U.S. culture, as well as among children of lesbian and gay parents in other countries. Finally, there is a clear positivity bias among our participants' views of their parents' sexual orientation. While all participants in our study are accepting of their parents and report positive relationships, there are certainly individuals who do not view their parents' lesbian and gay identities favorably. Future research would benefit from exploring the experiences of children who do not accept their parents' sexual orientation, though we imagine that sample would be difficult to obtain.

\section{Conclusion}

As parents are adjusting to a new identity and possibly disclosing on various levels and in varied contexts, the support of an experienced practitioner may be invaluable. In this study, children offered many points for parents to consider before, during, and following a comingout conversation. The overall suggestion that parents should reflect carefully on the possible ramifications, as well as various reactions that their children might have, provides a meaningful opportunity for practitioners to support lesbian and gay parents. The practical guidelines offered during the coming-out conversation might prove valuable for parents to visualize and preempt what might happen when they speak to their children. Similarly, the advice offered on how to manage a range of situations after a coming-out conversation with children illustrates the fact that coming out is a gradual and continuous process.

\section{References}

American Psychological Association. (2012). Guidelines for psychological practice with lesbian, gay, and bisexual clients. American Psychologist, 67, 10-42. doi:10.1037/a0024659

Barrett, H. B., \& Tasker, F. (2001). Growing up with a gay parent: Views of 101 gay fathers on their sons' and daughters' experiences. Educational and Child Psychology, 18, 62-77.

Baxter, L. A., \& Babbie, E. (2004). The basics of communication research. Belmont, CA: Wadsworth. 
Bozett, F. W. (1980). Gay fathers: How and why they disclose their homosexuality to their children. Family Relations, 29, 173-179. doi:10.2307/584068

Clay, J. W. (1990). Working with lesbian and gay parents and their children. Young Children, 45, 31-35.

Creswell, J. W. (2007). Qualitative inquiry \& research design: Choosing among the five approaches. Thousand Oaks, CA: Sage.

Goldberg, A. E. (2007). Talking about family: Disclosure practices of adults raised by lesbian, gay, and bisexual parents. Journal of Family Issues, 28, 100-131.

doi:10.1177/0192513X06293606

Lynch, J. M., \& Murray, K. (2000). For the love of the children: The coming out process for lesbian and gay parents and stepparents. Journal of Homosexuality, 39, 1-24. doi:10.1300/J082v39n01_01

Miles, M. B., \& Huberman, A. M. (1994). Qualitative data analysis (2nd ed.). Thousand Oaks, CA: Sage.

Patterson, C. J. (1992). Children of lesbian and gay parents. Child Development, 63, 10251042. doi:10.2307/1131517

Patterson, C. J. (1995). Lesbian mothers, gay fathers, and their children. In A. R.D'Augelli, \& C. J.Patterson (Eds.), Lesbian, gay and bisexual identities across the lifespan (pp. 262290). New York, NY: Oxford University Press. doi:10.1093/acprof:oso/9780195082319.003.0011

Smith, J. A. (1995). Semi-structured interviewing and qualitative analysis. In J. A.Smith, R.Harré, \& L. V.Langenhove (Eds.), Rethinking methods in psychology (pp. 9-26). Thousand Oaks, CA: Sage. doi:10.4135/9781446221792.n2

Turner, P. H., Scadden, L., \& Harris, M. B. (1990). Parenting in gay and lesbian families. Journal of Gay \& Lesbian Psychotherapy, 1, 55-66. doi:10.1300/J236v01n03_04

Weston, K. (1991). Families we choose: Lesbians, gays, kinship. New York, NY: Columbia University Press. 